\title{
Analysis of Operation Strategy and Management of University Gymnasiums
}

\author{
Fengquan $\mathrm{Yu}$ \\ Sports Sociology and Humanities, School of Sports Science, Nantong University, Nantong 226019, China
}

\begin{abstract}
With the progress of new trends of society, gymnasium, the most important part in Chinese sports facility, can not only meet the needs of physical exercise of students, but also provide a favorable place for social welfare development. But due to the influence of traditional management methods, some problems are still seen in the process of operation of university gymnasiums in china, which restricts the overall development of our country's sports enterprise. Therefore, this paper probes into the study on disadvantageous existed conditions and analyzes the operation strategies and management strategies of university gymnasiums on the basis of their characteristics and advantages.
\end{abstract}

Key words: Colleges and universities, gymnasiums, operation strategy, management strategy.

With the continuous development of the national economy, China's university gymnasiums are facing a comparatively great opportunity for development in operation management as well as facing greater development challenges. During the operation of university gymnasiums, the actual utilization of university gymnasiums are reduced due to the relatively low rate of opening, which not only failed to meet the enormous needs of modern sports development, but also affected the healthy development of sports. Therefore, analyzing operation strategies and management strategies of university gymnasiums has a greater significance.

\section{Characteristics of University Gymnasiums}

Resource of university ports facilities evolved from sports industry of universities. Generally, the features of university sports industry in the development process is mainly reflected in three aspects: welfare-oriented sports mode, amateur operating sports mode, sports mode with stable consumers. The modes are adopted differently to largely display the

Corresponding author: Fengquan Yu, M.S., lecturer, research field: sports economy and industry. salient features of certain universities according to their actual development conditions [1]. Further development could be also made through analyzing features of university sports industry and then applied them into the development of university gymnasiums. The service feature of university gymnasiums forms a special development mode due to summer and winter vacation. Such service mode determines the opening time of university gymnasiums each year. For opening time, there are mainly three opening modes of university ports facilities: existing regularly opening mode; seasonal opening pattern, especially during summer vacation and winter vacation; irregular opening mode. Their characteristics can be mainly divided into two kinds according to operating income and capital of university gymnasiums: one kind is self-used management; the other is partially paid by school and partially by self management [2]. The main mode of self-management is the analysis of the main flow of funds, including payment of labor, payment of utility bills, payment of sports expenditure and payment of teachers' bonuses and so on.

\section{Advantages of University Gymnasiums}

Compared with other social sports facilities, the 
advantages of university gymnasiums play a larger promoting role, among which university gymnasiums resources display great advantages of policy, personnel, information and material development and position development. Analysis of policy factor shows that the Chinese government makes plan of construction of university gymnasiums and stipulates clear policies of use form of resources. For example, according to the implementation of "Sports Law", the site configuration and equipment selection of school must be in accordance with certain standards and misappropriation with related excuses is not allowed. According to the positive development of talent factor, university is the main place for cultivating talents, which has qualified sports teachers who have received higher educated and not only has broad knowledge of sports, master sports science technology, have stronger organizational ability as well as teaching experience, but also can organize and carry out plans of related activities according to their abilities and experience. For information form, university gymnasiums can actively access to some latest sports news at home and abroad, and make a comprehensive use of related information so as to disseminate to important places [3]. Moreover, university has great advantages in information using form due to library established that contains a rich collection of books material and information of archives. For the material form, China's university sports facilities have advanced application of technology, in which the associated apparatus enable positive production of sports entities, and create basic conditions for the development of schools and country, guarantying the proper use of funds. For geographical position, Chinese universities are almost built in downtown or suburbs where environment is beautiful, traffic is convenient, more citizens living around the school, the relevant government agencies, primary school and secondary schools etc are around. At present, some of our colleges and universities have perfected the construction of sports facilities and have expanded university gymnasiums, not only elevating the level of university sports facilities, but also increasing opening time and grade of university sports facilities.

\section{Deficiency Existing in University Sports Facilities}

\subsection{The Phenomenon of Resource Deficiency}

According to the construction of sports facilities in China, it can be concluded that sports facilities of schools accounts for a relatively small proportion. For the actual development, there is a relatively huge shortage of sports resources in Chinese universities, in particular the shortage of funding becoming increasingly serious [4]. The varying degrees of facility problems are common in some universities, such as, the problem of outdated equipments, shortage of funds and so on. Such conditions will easily lead to low utilization, inadequate configuration of sports facilities, decrease of sports venues and per capita area facing greater shortage. There are many reasons why severe shortage of sports resources exists in university gymnasiums. Firstly, the deficient funds of university sports lead to fewer investments in facilities construction. Furthermore, the problem of outmoded equipments causes gymnasiums construction and numbers of students are proportionally large. This construction form will often lead to lack of exercise place to do physical education and fail to meet student's need of doing sports and active exercise in universities. The inadequate investment due to lacking sufficient funds during construction of university gymnasiums not only affects physical education is, but also lowers level of gymnasium's service for people's health [5]. Secondly, continuous college enrollment expansion results in continuous shortages of gymnasium teaching resource. That's because the implementation of college enrollment expansion do have brought greater development opportunities for universities, but on the other hand, some negative information has also been brought, such as, shortage of resources like accommodation, teacher resources, 
classroom and library in university. Even though related sports funds have been fully put into construction, the problems of insufficient gymnasiums and campus areas can not be resolved reasonably in short-term development due to enrollment expansion. Moreover, university gymnasiums are under repeated construction with low field specification and are limited by small scale, inadequate facilities and unity function, not only failing to meet the needs of students and teachers and a high-level sports competition, but also disabling universities effectively improve gymnasium's service efficiency [6].

\subsection{Narrow Operating Service}

In the existing operation model of university gymnasiums, the paid services has not been actively developed, nor multi-channel, multi-form and multi-level network services have been realized in society. Moreover, university gymnasiums, related facilities and the advantages of teachers have not been exploited in a relatively full way. China's sports facilities are largely established in schools while sports facilities and stadiums in schools are mainly used for teaching and training, without opening towards society. For example, according to analysis of specific constructions of 53 university gymnasiums in Liaoning Province, varying degrees of paid services account for a large proportion, but the utilization efficiency of college gymnasiums is still at a low stage. Therefore, the existing operation model of university gymnasiums leads to a great waste of resources. In particular the insufficiency existing in university gymnasiums, it is necessary to strengthen funds investment in facilities construction of university gymnasiums [7]. Secondly, university gymnasiums mainly serve for teaching and training, so the service time of university gymnasiums is after the use of time is generally after $8 \mathrm{am}$ in the morning and after $1 \mathrm{pm}$ in the afternoon, while other times is not for education. For example, on weekends and daily in the evening, gymnasiums are open free. For some high-end places that are well protected will not be actively used. In this form of development, although more investments were put into construction but it caused a serious waste of resources. Finally, university gymnasiums have few forms of social participation. The forms of some universities are limited within schools. Such enclosed form of development can indeed decrease large losses in the operations management. With years of construction and development of university gymnasiums, universities have fewer exchanges with social activities, which include many competitions, training and related activities that have not been effectively implemented, resulting in greater waste of resources of university gymnasiums.

\subsection{Backward Management of University Gymnasiums}

A greater backwardness existing in management of university gymnasiums in China is mainly because no high-quality, high-level talent personnel in the gymnasiums. In gymnasiums management in college, neither a strict management mechanism is formed, nor a professional management department is set to implement management especially the establishment and management form of paid services are still relatively weak. For example, the form of paid services of university gymnasiums are required to form a united development pattern in accordance with schools' related system, which should not only promote the form of supporting facilities, increase exchanges and coordination between sports departments and school leaders and strengthen relations between the two parties, but also should form supporting forms with working links of universities in order to promote normal operation of work. Currently, under the development conditions that unreasonable form of management and organization of paid service implemented by university gymnasiums and their far less perfect service system, active adjustments and further improving on paid services system of universities are sharply needed. We should not only vigorously develop a learning-based service model, 
but also construct group service form, and realize multi-level multi-angle service works on the basis of certain regional development so that paid service of university gymnasiums get active development. Currently, in the management, some university gymnasiums are under supervision of logistic staff and PE teachers, even under students in some university. In this form of management, university logistic staffs not only do not have relevant management knowledge or get some required training, but also have no effective mastery of knowledge related to sports. This pattern is inclined to property management, which easily suppresses operation model of university gymnasiums to a large extent. Among these phenomena, gymnasiums of a few universities are under supervision of PE teachers during management. And most gymnasiums are open seasonally, for example, swimming pools are open in summer vacation, which not only affects teachers' teaching efficiency, but also reduces the management quality of related managers. Besides certain sports knowledge the managers of university gymnasiums need to master, mastery of the scientific and rational management knowledge is also required. Only we probe into the study on deficiencies existing during management of university gymnasiums and then find out the reason for the development under this development, we can provide useful and beneficial development models to construction and operation of gymnasiums of Chinese universities.

\section{Operations Strategies for University Gymnasiums}

Implementation of strategy is the key element in operation of university gymnasiums. Making a scientific and rational strategy can promote the specific development of management and provide positive guidance advices. Therefore, developing a strategic plan for operation of university gymnasiums according to the actual situation of China's development is needed, and discussion and analysis of finance, the consumers and procedure should be conducted.

\subsection{Financial Strategy}

During the operation of university gymnasiums, the most important factor for development is positive use of finance, particularly in the initial opening stage. Great support should be given in operation and management of university gymnasiums. For universities, adequate funding should be provided in utility bills, purchasing equipment and other forms, among providing a certain amount of free health for teachers each year is suggested. For example, putting health point accumulated policy into practice and greatly support operation of university gymnasiums. At the same time, to realize cutting costs while increasing income, which can be improved from the following two aspects [8]. On one hand, making favorable development and utilization of existing resources of schools combined with traditional business on the basis of development pattern of core business. Besides, improving service and increasing propaganda about university gymnasiums, and taking new model of service as a basic condition, constantly improve university's brand images and also obtain more economic benefits from this form of development. On the other hand, the implemented financial strategy should effectively control operating costs, among which streamlining staffs is not only required, but also duplicated jobs are avoided so as to largely decrease the presence of waste.

\subsection{Consumer Strategy}

The implemented consumer strategy is a form of development that can meet interests of the main body and enhance need of value. Consumer strategy is the basis operation form of university gymnasiums which can reflect a diversity of consumer orientation during the process of implementation. Among them, you can create multiple and diverse forms of competition, and finish tasks organized by universities with a positive 
attitude, during which, we should actively keep in line with the national form of health and improve utilization efficiency of resources to a large extent. With this activity-oriented consumption form, not only active positions of universities are improved the in the community, but also positive role of university gymnasiums is promoted. Furthermore, positive development could be promoted between sports and other disciplines in this consumption channel, which can not only increase the consumer groups, but also make some mid-and-low-end customers as the actual target group so as to help schools obtain more economic income [9]. With this form of operation, service is everything. It is crucial to actively meet the needs of development of students, the largest customer groups. Weibo, Wechat and other publicity platforms are advised to propaganda university gymnasiums to meet the needs of exercise of students, in order to create more customer groups.

\subsection{Process Strategy}

Bring strategic management in the process. Firstly, establishing a series of highly efficient and professional operation teams, and increasing associated executive teams so as to take the specific operation forms as support condition of positive development during management. Then, strengthening the form of financial management and improving the utilization efficiency of various costs to a greater extent, particularly finance form is effectively implemented in controlling costs and benefits. Moreover, achieving innovative model of sustainable development, and promoting realization of operational objectives with diverse forms, in order to make sure that university gymnasiums can actively and stably operate. Finally, on the basis of existing service form, providing consumers with more value-added services, such as, free guidance, free body weighing and to achieve a unified, integrated database for consumers in order to improve the service quality of university gymnasiums.

\section{Management Strategies of University Gymnasiums}

\subsection{Establish Modern Management Concepts}

In operation management of university gymnasiums, the implementation of management strategy requires an established modern concept of development, and enhanced training of relevant staffs. In university gymnasiums, managers, as a basis for their development, not only have low overall quality and weak professional ability, but also directly affect the management level of university to gymnasiums. So for this development situation, relevant managers of university gymnasiums need to establish certain sense of development and realize the importance role they play in university gymnasiums. And modern management concepts should be propaganda among these managers to make them actively participate in the training work, and realize the combination of internal and external management model to improve professional level of the managers. For the form of personnel training, positive and careful selection of relevant managers considering interrogation of their internal culture and external knowledge. This form can not only initiate enthusiasm of the students with innovative form of management, but also helps to establish high-quality personnel, so as to pave an important basis for normal operation university gymnasiums. At the same time, it is necessary to establish a sound management system, which will not only effectively regulate the management of university gymnasiums, but also avoid some unreasonable factors in order to achieve effective mutual sharing of resources.

\subsection{Implementation Diversity Management}

Implement diversity management in university gymnasiums, and actively tap the potential of university gymnasiums. In specific management work, firstly, actively organizing relevant sports competitions, especially carrying out some 
high-quality sports events, and the establish alliance development of sports events nationwide, and achieving market-oriented management model according to the actual situation of development. During this management process, not only utilization efficiency of university gymnasiums is improved, but also universities get higher economic benefits. Then, investment channels should be expanded. Not only a reasonable way needed to make scientific plans of business condition and to promote upgrading mode, giving out health cards to public of the region is also necessary so as to promote the modern development of national fitness. Secondly, working hard to widen publicity, taking certain time as development deadline to establish friendly cooperative partnership with enterprises. Then according to the needs of university gymnasiums, taking advantage of their own development to increase events like concerts in university gymnasiums, inviting stars to be their ambassadors to improve the university brands and the status of university gymnasiums. Finally, establishing sports venues in universities that have overall services, among which relevant sports and fitness activities are contained into the venues. The forms of diversify management not only to bring more good services to people, but also continue to tap the potential of university gymnasiums in order to achieve power of sustainable development of university gymnasiums.

\subsection{Rational Design of University Gymnasiums}

According to development concept of "People-oriented", make rational design of university gymnasiums. Since university gymnasiums are relatively large in which more functions can be involved, a serious waste of resources would be caused if their designs are not reasonable. Therefore, for this case, the design concept of "People-oriented" should be actively taken into designs of university gymnasiums combined with aerobics in colleges and universities. Such form not only enables students learn in an entertaining way, but also help them master the theoretical knowledge and skill forms of aerobics in a relaxing atmosphere, in order to achieve rational development of design of university gymnasiums.

\section{Conclusion}

Operation of university gymnasiums is a comprehensive form of work. In order to improve the utilization of university gymnasiums and to achieve national exercise, the relevant managers of university gymnasiums should be fully aware of the importance of operations and management of university gymnasiums, and positively solve problems in all aspects with scientific and rational strategic thinking. Universities should not only strengthen the training of relevant personnel, but also should build high-quality professionals to improve actual operation and management level, so as to make positive decisions for the development of university gymnasiums.

\section{References}

[1] Zhu, H. Y. 2015. "Study on Operational Strategy and Management of University Gymnasiums.” Stationery and Science \& Technology 24 (10): 47.

[2] Zhou, E. E. 2013. "Research on the Gyms Operation Strategy and Management of Guangzhou Universities.” Ph.D. thesis, University of Technology.

[3] Jiang, W. C. 2013. "Research on Evaluation of Operational Performance of University Gymnasiums in Changsha.” Ph.D. thesis, Guangzhou Sport University.

[4] Bai, B., and Huang, Y. T. 2011. "Research on Application of Balanced Scorecard in the Management of University Gymnasiums.” College Newspaper of Harbin Sports University 29 (4): 79-81.

[5] Hu, Y. 2012. "Strategic Analysis of Diverse Operations of Large Gymnasiums during Post Olympic.” Chengdu Sport Institute 38 (4): 44-7.

[6] Liu, X. Q., and Feng, Y. H. 2013. "Construction of Operational Strategy Map of Comprehensive Gymnasiums after Guangzhou Asian Games.” Journal of Physical Education (6): 51-4.

[7] Ji, X. W. 2011. "The 11th National Games after Jinan Olympic Sports Center Stadiums Management Present Situation and Development Countermeasures.” Ph.D. thesis, Shandong Institute of P. E. and Sports.

[8] Xu, W. J. 2011. "Studies on Zhejiang Vocational College of Commerce Stadiums' Management Situation and Development Strategy.” Ph.D. thesis, Central China 
Normal University.

[9] Geng, B. Q. 2014. "Research on Life Cycle Management of Large-Scale Sports Venue.” Ph.D. thesis, Beijing Jiaotong University. 